\title{
EFEK VARIASI MASSA DAN ANALISA EFISIENSI BIOMASSA LIMBAH KAYU AKASIA DALAM PENGOLAHAN OPAK SINGKONG MENGGUNAKANKOMPOR BIOMASSA
}

\author{
Juandi $^{1 *}$, Ray Afriando ${ }^{1}$, Usman Malik ${ }^{1}$ \\ ${ }^{1}$ Jurusan Fisika Fakultas Matematika dan Ilmu Pengetahuan Alam Universitas Riau Kampus Binawidya Pekanbaru, 28293 \\ *e-mail: juandi@lecturer.unri.ac.id
}

\begin{abstract}
Abstrak
Telah dilakukan penelitian tentang "Efek Variasi Massa Dan Analisa Efisiensi Biomassa Limbah Kayu Akasia Dalam Pengolahan Opak Singkong Menggunakan Kompor Biomassa" dengan metode eksperimen. Kompor biomassa menggunakan energi biomassa dari limbah kayu akasia sebagai sumber energi atau bahan bakar dengan variasi massa $1200 \mathrm{gram}, 1000$ gram, dan 800 gram. Pengamatan dilakukan selama 60 menit dengan interval waktu 10 menit setiap pengamatan. Hasil penelitian untuk massa 1200 gram, $1000 \mathrm{gram}$, dan 800 gram mencapai nilai temperatur tertinggi yaitu $463^{\circ} \mathrm{C}$, laju energi panas yang hilang yaitu 514,439 Joule/s, laju energi panas yang terpakai yaitu 29176,323 Joule/s dengan kadar air yang hilang selama pengukusan yaitu 6,046 $\%$ dan massa jenis akhir yaitu 60,287 kg/m ${ }^{3}$. Efisiensi yang didapat berturut-turut yaitu 99,542\%, 99,270\%, dan 99,316\%.
\end{abstract}

Kata Kunci: Efisiensi, Kayu Akasia, Opak Singkong, Kompor Biomassa.

\begin{abstract}
[Title: Variation Of Mass Effect and Analysis Of The Efficiency Biomass Accacia Timber Waste In Processing Cassavas Opak Using Biomass Stove] Has conducted research on "Variation Of Mass Effect and Analysis Of The Efficiency Biomass Accacia Timber Waste In Processing Cassavas Opak Using Biomass Stove" using the experimental method. The biomass stoves is using biomass energy from accacia timber waste as an energy source or fuel with a variety of mass $1200 \mathrm{grams}, 1000$ grams, and 800 grams. The observations were carried out for 60 minutes with intervals of 10 minutes each observation. The research results show that at mass 1000 grams obtained value temperature highest of $463^{\circ} \mathrm{C}$. The average rate of heat energy is missing from the third variation mass 800 grams, 1000 grams, and 1200 grams receive is 514.439 Joule/s, and the average rate of energy heat elapsed of 29176.323 Joule/s with the water levels were lost during steaming of $6.046 \%$, and the average a mass of type the end of $60.287 \mathrm{~kg} / \mathrm{m}^{3}$. The efficiency obtained with the values respectively of $99.542 \%, 99.270 \%$, and $99.316 \%$.
\end{abstract}

Keywords: Efficiency, Accacia Timber, Cassavas Opak, Biomass Stove. 


\section{PENDAHULUAN}

Singkong (Manihot utilissima Pohl) yang lebih dikenal sebagai ketela pohon ataupun ubi kayu merupakan jenis tanaman perdu tahunan yang hidup di daerah tropis dan subtropis yang dapat tumbuh hampir di semua tempat (Nugroho dkk, 2013). Opak singkong merupakan salah satu olahan singkong dalam keadaan basah karena memiliki kandungan air yang cukup tinggi sehingga waktu simpan dalam bentuk segar sangat pendek dan tidak dapat bertahan lama. Opak singkong terbuat dari singkong yang dikupas terlebih dahulu, dibersihkan, dan diparut yang kemudian dicetak dengan menggunakan cetakan dari aluminium yang berbentuk lingkaran. Opak singkong yang telah dicetak selanjutnya dikukus selama 10 sampai dengan 15 menit. Opak singkong yang telah dikukus selanjutnya siap untuk dikeringkan.

Tujuan pengukusan adalah untuk menonaktifkan enzim yang akan menyebabkan perubahan warna, citarasa, dan nilai gizi yang tidak dikehendaki selama penyimpanan. Selain itu, tujuan dilakukannya pengukusan untuk mengurangi kadar air dalam bahan baku, sehingga tekstur bahan menjadi kompak

\section{(Sartika, 2009)}

Berdasarkan permasalahan tersebut maka dibuatlah alat pengolahan berupa kompor biomassa dengan teknologi pengolahan yang ramah lingkungan untuk memperbaiki kualitas olahan singkong dengan memanfaatkan energi biomassa yang berasal dari limbah kayu akasia sebagai sumber energi atau bahan bakar.Prinsip kerja alat ini adalah memanfaatkan panas yang tinggi dari pembakaran yang terjadi secara merata yang berasal dari pembakaran limbah kayu akasia di dalam ruangan pembakaran yang teradiasi ke atas dari bahan bakar ke sisi bagian luar dasar panci untuk mengalirkan udara panas ke ruangan pengukusan sehingga menghasilkan uap air panas sebagai media untuk mengukus opak singkong (M Juandidan O Panca, 2017).

Keuntungan pengukusan menggunakan kompor biomassa dengan energi biomassa yang digunakan berasal dari limbah kayu akasia sebagai sumber energi atau bahan bakar adalah tidak membutuhkan waktu yang cukup lama, ramah lingkungan dengan tidak menghasilkan banyak asap yang bisa mengganggu lingkungan sekitar, hemat energi, dan kualitas serta kebersihan makanan akan terjaga.

\section{METODE}

Penelitian ini dilakukan dengan menggunakan metode eksperimen yaitu dengan mendesain kompor biomassa menggunakan energi biomassa dari limbah kayu akasia yang dilakukan di Kelurahan Rejosari, Kecamatan Tenayan Raya, Kota Pekanbaru khususnya yang berkaitan dengan permasalahan untuk meningkatkan produktivitas usaha olahan singkong.

Kegiatan penelitian yang telah dilakukan dapat dilihat pada diagram alir penelitian Gambar dibawah ini :

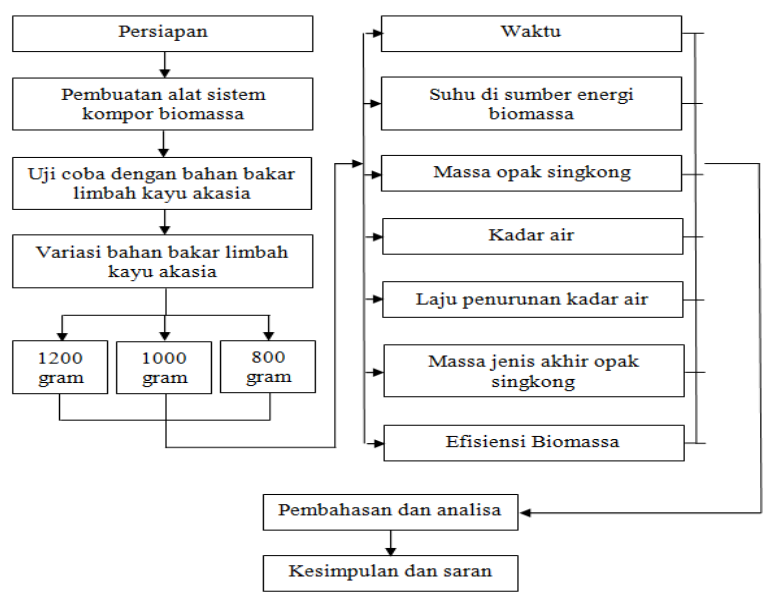

Gambar 1Diagram alir penelitian 
Prosedur penelitian ini dilakukan 3 (tiga) tahap, yaitu tahap mendesain alat, persiapan alat dan bahan, dan pengambilan data sepertiberikut :

1. Mendesain alat yang digunakan pada penelitian ini yaitu kompor biomassa dari limbah kayu akasia.

2. Menyiapkan alat dan bahan penelitian meliputi :

a) Kompor biomassa dari limbah kayu akasia dibuat dari kerangka plat seng dengan dinding seng yang dicat hitam sebagai penyerap panas. Menggunakan cerobong memanjang dibagian atasnya untuk mempercepat aliran udara. Membuat ruangan pengawetan yang terbuat dari plat seng bercat hitam yang dipasang menyatu dengan setiap dinding ruangan pembakaran.

b) Bahan bakar energi biomassa limbah kayu akasia dengan variasi massa 1200 gram,1000 gram, dan 800 gram yang telah mengalami pengeringan selama 1 hari dengan diberikan perlakuan yang sama.

c) Singkong segar yang dikupas terlebih dahulu, dibersihkan, dan diparut yang kemudian dicetak dengan menggunakan cetakan dari aluminium yang berbentuk lingkaran. Opak singkongyang telah dicetak selanjutnya dikukus selama 10 sampai dengan 15 menit diatas tungku kompor biomassa untuk pengolahan secara pengukusan menggunakan energi biomassa.

3. Pengambilan data.

Pengambilan data dilakukan setiap 10 menit yang terdiri dari pengukuran suhu di sumber energi biomassadalam ruangan pembakaran kompor biomassa, pengukur massa awalopak singkongserta massa akhiropak singkong, perubahan warna pada opak singkong, dan tingkatan kematangan dari opak singkong.

\section{HASIL DAN PEMBAHASAN}

Hasil pengamatan dari penelitian ditampilkan dalam bentuk tabel dan grafik. Data yang ditampilkan adalah nilai yang diukur selama 60 menit pengamatan.

\section{a. Suhu di Sumber Energi Biomassa di Dalam Ruangan Pembakaran Kompor Biomassa}

Data pengukuran suhu di sumber energi biomassa terhadap waktu pengukusan selama 60 menit dengan interval waktu 10 menit untuk setiap pengamatan ditunjukkan pada Tabel 1.

Tabel 1 Data suhu di sumber energi biomassa di dalam ruangan pembakarankompor bimassa

\begin{tabular}{|c|c|c|c|c|}
\hline \multirow[t]{2}{*}{ No. } & \multirow{2}{*}{$\begin{array}{c}\text { Waktu } \\
\text { Pengukusan } \\
\text { (Menit) }\end{array}$} & \multicolumn{3}{|c|}{$\begin{array}{c}\text { Subu di Sumber Energi Biomassa } \\
\text { ( } \mathrm{C} \text { ) }\end{array}$} \\
\hline & & $\mathrm{m}_{i]}$ & $\mathrm{m}_{\mathrm{b}_{2}}$ & $\mathrm{~m}_{63}$ \\
\hline 1 & 10 & 124 & 132 & 140 \\
\hline 2 & 20 & 185 & 170 & 176 \\
\hline 3 & 30 & 215 & 256 & 210 \\
\hline 4 & 40 & 264 & 295 & 242 \\
\hline 5 & 50 & 325 & 396 & 335 \\
\hline 6 & 60 & 413 & 463 & 415 \\
\hline
\end{tabular}

Data suhu di sumber energi biomassa di dalam ruangan pembakaran kompor biomassa digambarkan seperti Gambar 4.1.

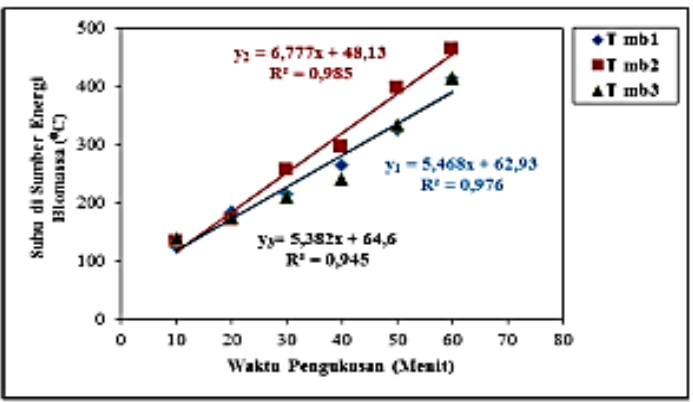

Gambar 4.1 Grafik hubungan suhu di sumber energi biomassa di dalam ruangan pembakaran kompor biomassa terhadap waktu pengukusan 


\section{b. Laju Energi Panas yang Hilang}

Data perhitungan laju energi panas yang hilang dari kompor biomassa dihitung dengan menggunakan Persamaan 2.5 yang ditampilkan pada Tabel 4.3.

Tabel 4.3 Data laju energi panas yang hilang dari kompor biomassa

\begin{tabular}{|c|c|c|c|c|}
\hline \multirow[t]{2}{*}{ No. } & \multirow[t]{2}{*}{$\begin{array}{c}\text { Waktu Pengikistsin } \\
\text { (Menil) }\end{array}$} & \multicolumn{3}{|c|}{$\begin{array}{l}\text { Laju Enetgi Panas yang Hillailg } \\
\text { (poule) }\end{array}$} \\
\hline & & thl & mo? & Mns \\
\hline 1 & 10) & 43,550 & 47,168 & 51,006 \\
\hline 2 & 20 & 77,141 & 67,521 & 71,254 \\
\hline 3 & 30 & 99,126 & 137,292 & 95,414 \\
\hline 4 & 4) & 145,787 & 182,480 & 123,325 \\
\hline S & 50 & 24,196 & 31,198 & 239,972 \\
\hline 6 & 60 & 388,257 & 514,439 & 392,804 \\
\hline
\end{tabular}

Data laju energi panas yang hilang dari kompor biomassa berenergi biomassa kayu akasiadigambarkan seperti Gambar 4.2.

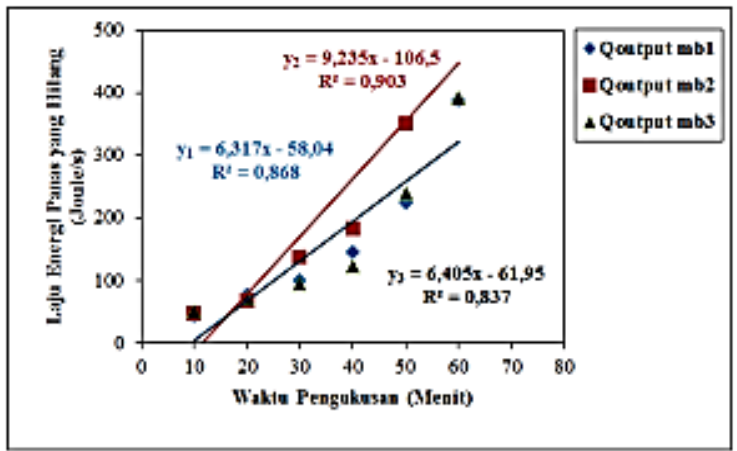

Gambar 4.2Grafik hubungan laju energi panas yang hilang dari komporbiomassa terhadap waktu pengukusan

\section{c. Laju Energi Panas yang Terpakai pada Kompor Biomassa}

Data perhitungan laju energi panas yang terpakai dari kompor biomassa ditampilkan pada Tabel 4.4.
Tabel 4.4 Data laju energi panas yang terpakai dari kompor biomassa

\begin{tabular}{|c|c|c|c|c|}
\hline \multirow[t]{2}{*}{ No. } & \multirow{2}{*}{ 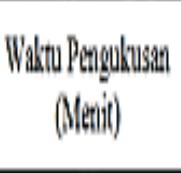 } & \multicolumn{3}{|c|}{ 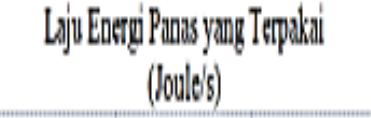 } \\
\hline & & 메 & Dn! & 10y \\
\hline 1 & 10 & 40149,730 & 33447,332 & 26744,514 \\
\hline$?$ & 20 & 40116,140 & 33426,879 & 26724,260 \\
\hline 3 & 30 & 40093,850 & 33357,108 & 26700,106 \\
\hline 4 & 40 & $400+7,490$ & 33311.920 & 26672.199 \\
\hline f & 50 & 39960,080 & 33113,222 & 26335,918 \\
\hline 6 & 60 & 39805,020 & 32979,961 & 26402,716 \\
\hline
\end{tabular}

Data laju energi panas yang terpakai dari kompor biomassa berenergi biomassa kayu akasiadigambarkan seperti Gambar 4.3.

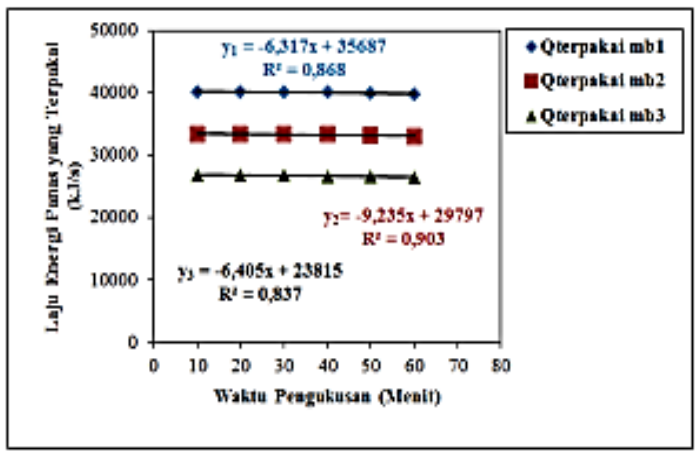

Gambar 4.3 Grafik hubungan laju energi panas yang terpakai dari kompor biomassa terhadap waktu pengukusan

\section{d. Efisiensi Sumber Energi Biomassa Menggunakan Kompor Biomassa}

Efisiensi sumber energi biomassa menggunakan kompor biomassa dihitung dengan menggunakan Persamaan 2.7. Hasil perhitungan efisiensi sumber energi biomassa menggunakan kompor biomassa dapat dilihat pada Tabel 4.8 
Tabel 4.8Data perhitungan efisiensi sumber energi biomassa

\begin{tabular}{|c|c|c|c|c|}
\hline \multirow[t]{2}{*}{ No. } & \multirow{2}{*}{$\begin{array}{c}\text { Wikto } \\
\text { Pengukusun } \\
\text { (Menit) }\end{array}$} & \multicolumn{3}{|c|}{$\begin{array}{c}\text { Efisitusi } \\
(\% 4)\end{array}$} \\
\hline & & $\underline{m}_{11}$ & $a_{i}$ & (14) \\
\hline 1 & 10 & 99,892 & 99,859 & 99,810 \\
\hline$?$ & 20 & 99,808 & 99,798 & 99,734 \\
\hline 3 & 30 & 99,753 & 99,990 & 99,644 \\
\hline 4 & 40 & 99,639 & 99,439 & 99,540 \\
\hline 5 & 50 & $99,4+2$ & 98,952 & 99,106 \\
\hline 6 & 60 & 99,034 & 98,464 & 98.534 \\
\hline
\end{tabular}

Data efisiensi sumber energi biomassa menggunakan kompor biomassa digambarkan seperti Gambar 4.7.

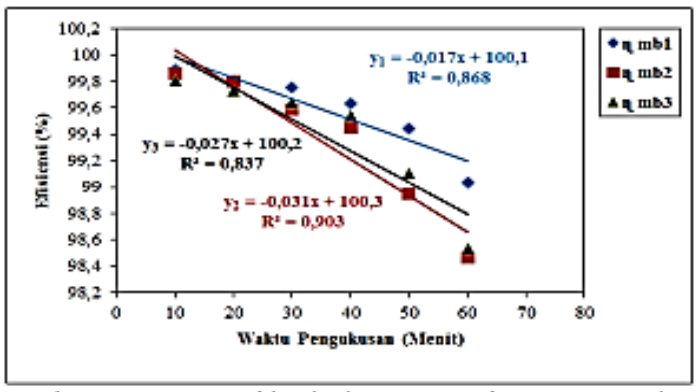

Gambar 4.7 Grafik hubungan efisiensi sumber energi biomassa terhadap waktu pengukusan

\section{KESIMPULAN}

Kesimpulan yang dapat diambil dari hasil pengamatan pada penelitian ini adalah sebagai berikut :

1. Kompor biomassa yang dibuat adalah berbentuk selinder yang dilengkapi dengan ruangan sirkulasi udara, ruangan pelindung selubung, tungku pembakaran, dan ruangan penampung abu pembakaran, yang semuanya dicat hitam dan menggunakan energi biomassa dari limbah kayu akasia sebagai sumber energi atau bahan bakar dengan variasi massa 1200 gram, 1000 gram, dan 800 gram.

2. Penelitian menunjukkan bahwa pada massa 1000 gram diperoleh nilai temperatur tertinggi yaitu $463^{\circ} \mathrm{C}$. Rata-rata laju energi panas yang hilang dari ketiga variasi massa 800 gram, 1000 gram, dan 1200 gram diperoleh sebesar 514,439 Joule/s, dan rata-rata laju energi panas yang terpakai yaitu 29176,323 Joule/s.

3. Efisiensi sumber energi biomassa menggunakan kompor biomassa untuk massa 1200 gram, 1000 gram, dan 800 gram yang digunakan selama 60 menit pengamatan didapat berturut-turut yaitu 99,542\%, 99,270\%, dan 99,316\%.

\section{DAFTAR PUSTAKA}

M Juandi, O Panca, 2017, Efek Variasi Massa dari Biomassa Limbah Tempurung Kelapa terhadap Laju Penurunan Kadar Air sebagai Fungsi Waktu Hasil Pengeringan Buah Pinang dengan Alat Pengering Tipe Kabiner, Jurnal APTEK, Volume 9, No. 1

Nugroho, J.W.K., Destiani Supeno, dan Nursigit Bintoro. 2013 Pengeringan Kerupuk Singkong Menggunakan Pengering Tipe Rak. Lembaga Penelitian Universitas Lampung.

Sartika, R.A.D. 2009. Pengaruh Suhu dan Lama Proses Mengukus terhadap Pembentukan Asam Lemak Trans. Makaira Sains I: 23-28. 